\title{
Dansk Industri: nadere afbakening grenzen aan richtlijnconforme interpretatie en horizontale werking algemeen Unierechtelijk beginsel?
}

\author{
Mr. S.W. Haket*
}

In het arrest Dansk Industri oordeelt het Hof van Justitie dat het de nationale rechter niet is toegestaan enkel op basis van vaste rechtspraak de mogelijkheid van een richtlijnconforme interpretatie van een nationale bepaling af te wijzen. Indien de nationale bepaling desondanks niet richtlijnconform kan worden geïnterpreteerd, dient zij buiten toepassing te worden gelaten voor zover zij onverenigbaar is met het algemene verbod van discriminatie op grond van leeftijd. Het rechtszekerheidsbeginsel doet hier niet aan af.

Hvf 19 april 2016, zaak C-441/14, Dansk Industri
(DI)/Nalatenschap van Karsten Eigil Rasmussen,
ECLI:EU:C:2016:278

\section{Het hoofdgeding}

Bij het Deense Hooggerechtshof is een geding aanhangig tussen Dansk Industri, als lasthebber van Ajos A/S, en de erfgenamen van K.E. Rasmussen (hierna: Rasmussen) betreffende de weigering aan Rasmussen een speciale ontslagvergoeding toe te kennen. De speciale ontslagvergoeding is bedoeld om de herintreding in het arbeidsproces van werknemers met een anciënniteit van (minstens) twaalf jaar in de onderneming, te bevorderen. ${ }^{1}$ Met betrekking tot de toekenning van de speciale ontslagvergoeding ter hoogte van drie maanden salaris vereist de Deense wetgeving dat de werknemer gedu-

Mr. S.W. (Sim) Haket LLM is als promovendus verbonden aan het Montaigne Centrum voor Rechtspleging en Conflictoplossing van de Universiteit Utrecht.

1. Zie voor vaststelling van het oogmerk van de nationale regeling de voorloper van het arrest Dansk Industri, HvJ 12 oktober 2010, zaak C-499/08, Ingeniørforeningen i Danmark, ECLI:EU:C:2010:600, punt 29. rende achttien jaar in dezelfde onderneming tewerkgesteld is geweest. Rasmussen voldeed aan dit criterium, en wenste zijn beroepsloopbaan voort te zetten, maar omdat hij ten tijde van de beëindiging van de arbeidsverhouding recht had op een ouderdomspensioen van de werkgever verviel volgens de nationale regeling, zoals uitgelegd in vaste rechtspraak, zijn recht op de speciale ontslagvergoeding.

Rasmussen deed een beroep op het arrest Ingeniorforeningen $i$ Danmark, waarin het Hof van Justitie had geoordeeld dat artikel 2 en artikel 6 lid 1 Richtlijn 2000/78/EG (hierna: Richtlijn gelijke behandeling) ${ }^{2}$ aldus moeten worden uitgelegd dat zij zich verzetten tegen een nationale regeling waarbij werknemers die recht hebben op een ouderdomspensioen van de werkgever, alleen op die grond niet in aanmerking komen voor een speciale ontslagvergoeding waarmee wordt beoogd het herintreden van werknemers met een anciënniteit van (minstens) twaalf jaar in de onderneming, te bevorderen. ${ }^{3}$ Dit arrest betrof een geschil tussen een particulier en de overheid. Het hier besproken arrest betreft een geschil tussen particulieren. Om die reden concludeerde het Deense Hooggerechtshof dat Rasmussen zich niet rechtstreeks op de Richtlijn gelijke behandeling kon beroepen. In de verwijzingsbeslissing wijst het Deense Hooggerechtshof er voorts op dat volgens zijn vaste rechtspraak de nationale bepaling, volgens welke het recht op de speciale ontslagvergoeding vervalt indien de werknemer ten tijde van de beëindiging van de arbeidsverhouding een ouderdomspensioen van de werkgever zal ontvangen, ook wordt toegepast in de situatie waarin een werknemer het pensioen kan ontvangen, maar ervoor kiest daarvan tijdelijk af te zien om

2. Richtlijn $2000 / 78 /$ EG van de Raad van 27 november 2000 tot instelling van een algemeen kader voor gelijke behandeling in arbeid en beroep, PbEG 2000, L303/16.

3. Ingeniørforeningen i Danmark, punt 49 
zijn beroepsloopbaan elders voort te zetten. ${ }^{4}$ Tegen deze achtergrond zou een uitlegging van de nationale bepaling in overeenstemming met de Richtlijn gelijke behandeling, zo overweegt het Deense Hooggerechtshof, contra legem zijn. Het Deense Hooggerechtshof wenst daarom te vernemen of het algemene Unierechtelijke verbod van discriminatie op grond van leeftijd kan worden ingeroepen tegen een particuliere werkgever om deze te verplichten de speciale ontslagvergoeding te betalen. Met de prejudiciële verwijzing stelt het Deense Hooggerechtshof de werking van het algemene verbod van discriminatie op grond van leeftijd in een geschil tussen particulieren aan de orde. Het vraagt in het bijzonder naar de ruimte om het algemene verbod en de, in zijn woorden, rechtstreekse werking daarvan, af te wegen tegen het rechtszekerheidsbeginsel en het beginsel van bescherming van het gewettigd vertrouwen. Ten slotte vraagt het of het voor de beoordeling van de mogelijkheid van een dergelijke afweging van belang is dat de werknemer eventueel een vordering tot staatsaansprakelijkheid kan instellen.

\section{De prejudiciële beslissing}

De eerste prejudiciële vraag betreft de omvang van het algemene verbod van discriminatie op grond van leeftijd. Uit de overwegingen van het Hof van Justitie blijkt dat de relatie tussen het algemene verbod en de Richtlijn gelijke behandeling bijzondere aandacht vereist. Het Hof van Justitie overweegt wat betreft deze relatie dat de draagwijdte van de door de Richtlijn gelijke behandeling verleende bescherming niet verder gaat dan die van het algemene verbod van discriminatie op grond van leeftijd. De Richtlijn gelijke behandeling biedt een nauwkeuriger kader om de concrete toepassing van het algemene verbod te vergemakkelijken. ${ }^{5}$ Het Hof van Justitie overweegt dat de nationale regeling

(...) door op algemene wijze een hele categorie werknemers van de speciale ontslagvergoeding uit te sluiten, de voorwaarden voor ontslag van deze werknemers in de zin van artikel 3, lid 1, onder c), van richtlijn 2000/78 betreft. Hieruit volgt dat de in het hoofdgeding aan de orde zijnde nationale regeling binnen de werkingssfeer van het Unierecht, en bijgevolg binnen die van het algemene verbod van discriminatie op grond van leeftijd, valt. ${ }^{6}$

In antwoord op de eerste vraag concludeert het Hof van Justitie dat

(...) het algemene verbod van discriminatie op grond van leeftijd, zoals dat concreet gestalte heeft gekregen in richtlijn 2000/78, aldus moet worden uitgelegd dat het zich, ook in een geschil tussen particulieren, ver- zet tegen een nationale regeling als aan de orde in het hoofdgeding $(\ldots)^{7}$

In zijn antwoord op de tweede prejudiciële vraag wijst het Hof van Justitie eerst op de verplichting tot richtlijnconforme interpretatie, die tevens inhoudt

(...) om in voorkomend geval vaste rechtspraak te wijzigen wanneer deze berust op een met de doelstellingen van een richtlijn onverenigbare uitlegging van het nationale recht. Bijgevolg kan de verwijzende rechterlijke instantie in het hoofdgeding niet op goede gronden oordelen dat zij de betrokken nationale bepaling niet in overeenstemming met het Unierecht kan uitleggen op de enkele grond dat zij deze bepaling tot dan toe steeds heeft uitgelegd op een wijze die onverenigbaar is met het Unierecht. ${ }^{8}$

Onder verwijzing naar het arrest Kücükdeveci, overweegt het Hof van Justitie vervolgens dat,

(...) zelfs al zou een nationale rechterlijke instantie die uitspraak dient te doen in een geding waarin het algemene verbod van discriminatie op grond van leeftijd, zoals dat concreet gestalte heeft gekregen in richtlijn 2000/78, aan de orde is, daadwerkelijk in de onmogelijkheid verkeren het nationale recht richtlijnconform uit te leggen, zij niettemin verplicht is, in het kader van haar bevoegdheden de voor de justitiabelen uit het Unierecht voortvloeiende rechtsbescherming te verzekeren en de volle werking daarvan waarborgen, waarbij zij indien nodig elke met dit verbod strijdige nationale bepaling buiten toepassing moet laten. ${ }^{9}$

Nadat het Hof van Justitie heeft gewezen op de verplichting tot richtlijnconforme interpretatie, en de verplichting de met het algemene verbod van discriminatie op grond van leeftijd strijdige nationale bepaling buiten toepassing te laten, concludeert het dat het rechtszekerheidsbeginsel, en het beginsel van bescherming van het gewettigd vertrouwen, niet afdoen aan deze verplichting. Hiertoe overweegt het:

[d]e toepassing van het beginsel van bescherming van het gewettigd vertrouwen die de verwijzende rechterlijke instantie voor ogen staat, zou er immers in feite op neerkomen dat de gevolgen van de door het Hof gegeven uitlegging in de tijd worden beperkt, omdat daarmee die uitlegging niet van toepassing zou zijn in het hoofdgeding. ${ }^{10}$

Het Hof van Justitie wijst erop dat, behoudens in zeer uitzonderlijke omstandigheden, die zich in casu niet

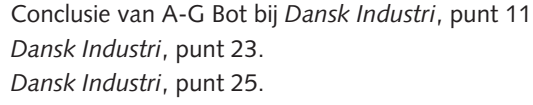

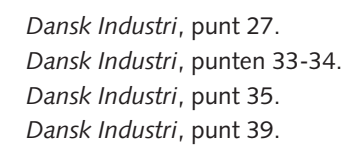


voordeden, de gegeven uitlegging ex tunc werkt. ${ }^{11}$ Hier voegt het aan toe dat

(...) de bescherming van het gewettigd vertrouwen in elk geval niet kan worden ingeroepen om aan een particulier die de rechtsvordering heeft ingesteld die het Hof ertoe heeft gebracht het Unierecht aldus uit te leggen dat het in de weg staat aan de betrokken nationale regel, het voordeel van die uitlegging te weigeren. $^{12}$

De mogelijkheid van staatsaansprakelijkheid doet hieraan niet af. ${ }^{13}$

\section{Analyse}

Aan de verwijzingsbeslissing ligt de vraag ten grondslag welke gevolgen uitgaan van de in het arrest Ingeniorforeningen $i$ Danmark door het Hof van Justitie aan de Richtlijn gelijke behandeling gegeven interpretatie in een geschil tussen particulieren dat dezelfde nationale regeling betreft. Het Hof van Justitie herhaalt in Dansk Industri het welbekende verbod van rechtstreekse werking van richtlijnbepalingen in een geschil tussen particulieren (verbod van horizontale rechtstreekse werking). ${ }^{14}$ In de daaropvolgende overwegingen wijst het Hof van Justitie op twee verplichtingen die de volle werking van het Unierecht ten goede komen: de verplichting tot richtlijnconforme interpretatie, en het buiten toepassing laten van een nationale bepaling die strijdig is met het algemene verbod van discriminatie op grond van leeftijd. Mijn analyse van arrest Dansk Industri is toegespitst op de benadering door het Hof van Justitie ten aanzien van deze twee verplichtingen.

\section{Richtlijnconforme interpretatie}

Uit de verwijzingsbeslissing van het Deense Hooggerechtshof blijkt dat het de mogelijkheid van een richtlijnconforme interpretatie heeft overwogen en, omdat naar zijn oordeel als gevolg van vaste nationale rechtspraak zo een interpretatie in strijd is met het verbod van een interpretatie contra legem, ${ }^{15}$ zijn prejudiciële vragen heeft toegespitst op de werking van het algemene verbod van discriminatie op grond van leeftijd in een geschil tussen particulieren. Ondanks de conclusie van het Deense Hooggerechtshof dat een richtlijnconforme interpretatie in strijd is met het verbod van een interpretatie contra legem, betrekt het Hof van Justitie de verplichting tot richtlijnconforme interpretatie in het antwoord op de tweede prejudiciële vraag, en geeft bij deze gelegenheid een nadere precisering van haar inhoud.

Het is niet zozeer de mogelijkheid van een richtlijnconforme interpretatie, meer in het bijzonder de betekenis van het begrip contra legem, dat ik nader bespreek. In plaats daarvan analyseer ik het arrest Dansk Industri met het oog op de vraag of het Hof van Justitie de bevoegdheid van de nationale rechter te oordelen over de interpretatie van nationaal recht doorkruist. Ten behoeve van deze analyse beschrijf ik eerst de rol die het Hof van Justitie en de nationale rechter respectievelijk vervullen in het kader van richtlijnconforme interpretatie. Ik begin bij laatstgenoemde. De nationale rechter is uiteindelijk bevoegd te oordelen of nationaal recht richtlijnconform kan worden geïnterpreteerd. Deze bevoegdheid volgt logischerwijze uit een syllogistische redenering, waarbij de majorpremisse bestaat uit het feit dat de uitlegging van het nationale recht de exclusieve taak van de nationale rechter is, ${ }^{16}$ en de minorpremisse verwijst naar de omstandigheid dat de mogelijkheid van een richtlijnconforme interpretatie afhangt van de uitlegging van het nationale recht. Aangezien het Hof van Justitie bevoegd is het Unierecht te interpreteren, is het tevens bevoegd de verplichting tot richtlijnconforme interpretatie te verduidelijken, omdat die verplichting is gebaseerd op artikelen $288 \mathrm{VWEU}$ en 4 lid $3 \mathrm{VEU}$. In arresten zoals Marleasing en Pfeiffer wordt de verplichting tot richtlijnconforme interpretatie nader geïnterpreteerd, en spoort het Hof van Justitie de nationale rechter aan zich maximaal in te spannen om een richtlijnconform uitlegresultaat te bereiken. ${ }^{17}$ Hierbij speelt de volle werking van het Unierecht een belangrijke rol. Zowel het belang van de volle werking van het Unierecht als de erkenning dat de verplichting van de nationale rechter tot richtlijnconforme interpretatie niet onbegrensd is, wordt in Pfeiffer kernachtig weergegeven met de overweging dat die verplichting ' $(. .$.$) de nationale rechter in staat stelt$

16. Adeneler, punt 103

17. In HvJ 13 november 1990, zaak C-106/89, Marleasing, ECLI:EU:C: 1990:395, punt 8, overweegt het Hof van Justitie: '[b]ij de toepassing van het nationale recht, ongeacht of het daarbii gaat om bepalingen die dateren van eerdere of latere datum dan de richtliin [cursivering; $\mathrm{SWH}$, moet de nationale rechter dit zoveel mogelijk uitleggen in het licht van de bewoordingen en het doel van de richtlijn'. In Pfeiffer, punt 116, overweegt het Hof van Justitie: '[w]anneer het nationale recht het door de toepassing van de daarin erkende uitleggingsmethoden in bepaalde omstandigheden mogelijk maakt om een bepaling van de nationale rechtsorde aldus uit te leggen dat een conflict met een andere bepaling van nationaal recht wordt vermeden of om met dit doel de strekking van die bepaling te beperken door haar slechts toe te passen voor zover zij met die andere bepaling verenigbaar is, is de rechter verplicht dezelfde methoden te gebruiken om het door de richtlijn beoogde resultaat te bereiken'.
15. HvJ 16 juni 2005, zaak C-105/03, Pupino, ECLI:EU:C:2005:386, punt 47 , evenwel in de context van kaderbesluitconforme interpretatie. Het verbod van een interpretatie contra legem werd voor het eerst herhaald in de context van richtlijnconforme interpretatie in HvJ 4 juli 2006, zaak C-212/04, Adeneler, ECLI:EU:C:2006:443, punt 110. 
binnen het kader van zijn bevoegdheden de volle werking van het gemeenschapsrecht te verzekeren (...)'. ${ }^{18}$

Uit het voorgaande volgt dat (in het kader van de verplichting tot richtlijnconforme interpretatie) het Hof van Justitie de bevoegdheid van de nationale rechter doorkruist indien het aan de nationale rechter impliciet of expliciet voorschrijft hoe nationaal recht dient te worden geinterpreteerd. Doorkruist het Hof van Justitie in Dansk Industri de bevoegdheid van de nationale rechter door zich te bemoeien met de mogelijkheid om het nationale recht richtlijnconform te interpreteren? Het is van belang voor deze vraag onderscheid te maken tussen een inperking van de interpretatievrijheid van de nationale rechter, en een doorkruising van zijn bevoegdheid. De enkele omstandigheid dat het Hof van Justitie in Dansk Industri - ondanks het oordeel van het Deense Hooggerechtshof over de onmogelijkheid het nationale recht in overeenstemming met de richtlijn uit te leggen in de verwijzingsbeslissing - toch ingaat op de verplichting tot richtlijnconforme interpretatie, en met zijn overwegingen grenzen stelt aan de ruimte voor het Deense Hooggerechtshof om te oordelen over de mogelijkheid van een richtlijnconforme interpretatie, is naar mijn opvatting niet voldoende om een doorkruising van de bevoegdheid van de nationale rechter vast te stellen. Dat de interpretatievrijheid van de nationale rechter op enigerlei wijze wordt geraakt, is inherent aan de verplichting tot richtlijnconforme interpretatie. ${ }^{19}$ Aldus dient de aard en omvang van deze inperking in Dansk Industri te worden vastgesteld om te kunnen beoordelen of deze inperking de bevoegdheid van de nationale rechter doorkruist. Zoals hierboven reeds vermeld overweegt het Hof van Justitie dat het Deense Hooggerechtshof niet op goede gronden kon oordelen dat de nationale bepaling niet richtlijnconform kon worden uitgelegd op de enkele grond dat het die bepaling tot dan toe steeds heeft uitgelegd op een wijze die onverenigbaar is met het Unierecht. Wat betreft de aard van de inperking zij opgemerkt dat het Hof van Justitie niet een bepaald uitlegresultaat van de nationale bepaling voorschrijft, en evenmin schrijft het een bepaalde interpretatiemethode voor. ${ }^{20}$ Wat betreft de omvang van de inperking bieden de passages inzake richtlijnconforme interpretatie mijns inziens twee aanknopingspunten. Allereerst wordt de mogelijkheid voor de nationale rechter om te concluderen dat een richtlijnconforme interpretatie niet mogelijk is alleen uitgesloten voor zover die conclusie enkel gebaseerd is op vaste rechtspraak ten aanzien van een nationale bepaling. De overwegingen in Dansk Industri bieden geen basis voor de gevolgtrekking dat denkelijk met het bestaan van vaste rechtspraak samenhangende bezwaren tevens zijn uitgesloten. Hier zou bijvoorbeeld

18. Pfeiffer, punt 114.

19. Dit volgt reeds uit HvJ 10 april 1984, zaak 14/83, Von Colson en Kamann, ECLI:EU:C:1984:153, waarmee de verplichting tot richtlijnconforme interpretatie werd gevestigd; A. Arnull, 'The law lords and the European Union: swimming with the incoming tide', European law review 2010, p. 70.

20. Vgl. HvJ 16 december 1993, zaak C-334/92, Wagner Miret, ECLI:EU:C: 1993:945, punt 20. kunnen worden gedacht aan de mogelijkheid om onder bepaalde omstandigheden een beroep te doen op het rechtszekerheidsbeginsel indien wordt afgeweken van vaste rechtspraak. ${ }^{21}$ De bevoegdheid van de nationale rechter wordt mijns inziens dus in beperkte mate geraakt. Dit wordt bevestigd door het tweede aanknopingspunt. In de passages betreffende de verplichting tot richtlijnconforme interpretatie blijft de grondgedachte dat de nationale rechter 'zoveel mogelijk' richtlijnconform moet interpreteren, daarbij rekening houdende met de in het nationale recht erkende uitleggingsmethoden, overeind. ${ }^{22}$ Hiermee wordt aan de nationale rechter ruimte gelaten om te oordelen of richtlijnconforme interpretatie van het nationale recht daadwerkelijk mogelijk is. ${ }^{23}$ De twee aanknopingspunten uit Dansk Industri worden bevestigd doordat de passage waarin de verplichting tot het wijzigen van vaste rechtspraak is opgenomen verwijst naar het arrest Centrosteel. Dit betrof net als Dansk Industri een situatie waarin enkel een beroep werd gedaan op een eerder gevolgde interpretatie in de nationale rechtspraak; dit bevestigt dat het Hof van Justitie geen ruimere strekking beoogt met zijn overweging in Dansk Industri. Daarnaast kan de passage uit Centrosteel waarin de nationale rechter wordt verplicht om vaste rechtspraak te wijzigen, net als in Dansk Industri, niet los worden gezien van de aanwijzing 'zoveel mogelijk' richtlijnconform te interpreteren. Deze aanwijzing wordt vermeld in de voorafgaande passage, waarnaar blijkens de aanhef ('aldus') wordt terugverwezen in de passage betreffende het wijzigen van vaste rechtspraak. ${ }^{24}$ Er is echter ook een verschil ten opzichte van Centrosteel. In dat arrest wees het Hof van Justitie de verwijzende Italiaanse rechter erop dat het Corte suprema di cassazione zijn rechtspraak al conform de richtlijn had aangepast. ${ }^{25}$ Hieruit bleek reeds de mogelijkheid de nationale bepaling richtlijnconform te interpreteren. Een dergelijke aanwijzing ontbreekt in Dansk Industri, maar dit betekent niet dat de bevoegdheid van de nationale rechter wordt doorkruist.

Gelet op de aard en omvang van de inperking van de interpretatievrijheid van de nationale rechter is mijn conclusie dat het Hof van Justitie in Dansk Industri de bevoegdheid van de nationale rechter om te oordelen over de interpretatie van nationaal recht niet doorkruist. Tot slot zij opgemerkt dat, wanneer het bestaan van enkel vaste rechtspraak een richtlijnconform uitlegresultaat zou kunnen verhinderen, dit erop neerkomt dat de oorzaak van de onverenigbaarheid tevens de legitimatie vormt voor haar voortbestaan. Daarmee zou de betekenis van het instrument van de richtlijnconforme interpretatie, en de volle werking van het Unierecht, aan-

21. G. Guillaume, 'The use of precedent by international judges and arbitrators', Journal of International Dispute Settlement 2011, p. 5.

22. Dansk Industri, punt 31.

23. Zie voor deze betekenis van het 'zoveel mogelijk' richtlijnconform interpreteren, M. Wissink, 'Interpretation of private law in conformity with EU directives', in: A.S. Hartkamp e.a., The influence of EU law on national private law, Deventer: Kluwer 2014, p. 124.

24. HvJ 13 juli 2000, zaak C-456/98, Centrosteel, ECLI:EU:C:2000:402, punten 16-17.

25. Centrosteel, punt 17. 
zienlijk worden beperkt. Ook vanuit dit perspectief is het oordeel van het Hof van Justitie goed te rechtvaardigen.

\section{Buiten toepassing laten nationale bepaling op grond van het algemene verbod van discriminatie op grond van leeftijd}

Indien een richtlijnconforme interpretatie daadwerkelijk niet mogelijk is, dient volgens het Hof van Justitie de volle werking van het Unierecht te worden verzekerd door de met het algemene verbod van discriminatie op grond van leeftijd onverenigbare nationale bepaling buiten toepassing te laten. Hiermee verwijst het Hof van Justitie naar de doorwerkingsroute à la Mangold, ${ }^{26}$ en in het bijzonder de nadere verfijning daarvan in het arrest Kücükdeveci. ${ }^{27}$ Het Deense Hooggerechtshof spreekt zelf van 'rechtstreekse werking', maar die kwalificering wordt door het Hof van Justitie niet gebruikt; ik laat dit aspect in mijn analyse verder buiten beschouwing en sluit aan bij de formulering door het Hof van Justitie. ${ }^{28}$ Uit Dansk Industri leid ik af dat het Hof van Justitie twee voorwaarden hanteert voor toepassing van de doorwerkingsroute, die eerder in Kücükdeveci konden worden teruggevonden. ${ }^{29}$ Toepassing van deze doorwerkingsroute vereist allereerst dat de nationale regeling binnen de werkingssfeer van het Unierecht valt. ${ }^{30}$ Deze eerste voorwaarde wordt blijkens het antwoord op de eerste prejudiciële vraag vervuld, in welk kader het Hof van Justitie overweegt dat de nationale regeling ' $(. .$.$) de$ voorwaarden voor ontslag in de zin van artikel 3 , lid 1 , onder c), van richtlijn 2000/78 betreft'. ${ }^{31}$ Zoals reeds bleek uit Kücükdeveci ${ }^{32}$ en tevens uit Römer $^{33}$ is het niet van belang dat de nationale regeling geen omzettingsregeling betreft, maar is het voldoende dat zij ratione materiae binnen de werkingssfeer van het Unierecht valt. ${ }^{34}$ De tweede voorwarde is dat Unierecht is geschonden. Voor de beoordeling of zulks het geval is, wordt (evenals in Kücükdeveci) de nationale regeling de facto getoetst

26. HvJ 22 november 2005, zaak C-144/04, Mangold, ECLI:EU:C 2005:709.

27. HvJ 19 januari 2010, zaak C-555/07, Kücükdeveci, ECLI:EU:C:2010:21.

28. Zie over de kwalificering van de doorwerkingsroute à la Mangold en Kücükdeveci als rechtstreekse werking, E. Muir, 'Of ages in - and edges of - EU law', Common market law review 2011, p. 54 e.v.

29. Zie ook Muir 2011, p. 52-53.

30. Dansk Industri, punt 24. Vgl. Kücükdeveci, punt 23.

31. Dansk Industri, punt 25

32. Kücükdeveci, punt 25

33. HvJ 10 mei 2011, zaak C-147/08, Römer, ECLI:EU:C:2011:286, punt 63.

34. L. Pech, 'Between judicial minimalism and avoidance: the Court of Justice's sidestepping of fundamental constitutional issues in Römer and Dominguez', Common market law review 2012, p. 1864 aan de Richtlijn gelijke behandeling. ${ }^{35}$ Het Hof van Justitie stelt vast dat de Richtlijn gelijke behandeling zich verzet tegen de nationale regeling. Vervolgens overweegt het dat dezelfde conclusie dient te gelden voor het algemene verbod, en aldus verzet '(...) het algemene verbod van discriminatie op grond van leeftijd, zoals dat concreet gestalte heeft gekregen in richtlijn 2000/78 (...)', zich tegen de nationale regeling. ${ }^{36}$ Omdat aan beide voorwaarden is voldaan treedt het rechtsgevolg van het buiten toepassing laten van de nationale bepaling in. Hoewel de richtlijn het de facto toetsingskader biedt, is het algemene verbod het de jure toetsingskader waarop het buiten toepassing laten wordt gebaseerd. ${ }^{37}$

Vervolgens gaat het Hof van Justitie in op de betekenis van het rechtszekerheidsbeginsel en het beginsel van bescherming van het gewettigd vertrouwen. De vraag of de mogelijkheid van staatsaansprakelijkheid in dit kader van belang is, zal ik niet bespreken, omdat de irrelevantie hiervan redelijkerwijze kan worden afgeleid uit de door het Hof van Justitie in Dominguez aangebrachte volgorde van de doorwerkingsinstrumenten. ${ }^{38}$ Het Hof van Justitie ziet de toepassing van het rechtszekerheidsbeginsel zoals het Deense Hooggerechtshof dit voor ogen heeft als een beperking in de tijd van de door hem gegeven uitlegging. Zo een beperking is slechts in zeer uitzonderlijke omstandigheden toegestaan, waarvan het bestaan in het onderhavige geding niet is aangevoerd. Met deze inkadering betrekt het Hof van Justitie het door het Deense Hooggerechtshof naar voren gebrachte rechtszekerheidsbeginsel op de algemene vraag wat het belang is van de mogelijkheid voor een particulier om de omvang van een uit het Unierecht voortvloeiende verplichting te kennen. Ik typeer deze vraag als 'algemeen' om duidelijk te maken dat de benadering van het Hof van Justitie in elk geval niet is toegespitst op de specifieke aard van de doorwerkingsroute à la Mangold en Kücükdeveci, maar een algemener karakter heeft. Dit blijkt ook uit het dictum. Daarin wordt zowel de verplichting tot richtlijnconforme interpretatie als het buiten toepassing laten genoemd. Vervolgens vermeldt het dat het rechtszekerheidsbeginsel en het beginsel van bescherming van het gewettigd vertrouwen niet afdoen aan 'deze verplichting'. Met 'deze verplichting' lijkt het naar allebei de doorwerkingsinstrumenten te verwijzen, en dus niet uitsluitend de doorwerkingsroute à la Mangold en Kücükdeveci. Opgemerkt dient te worden dat het Deense Hooggerechtshof een meer specifiek probleem voor ogen lijkt te hebben gehad. In de verwijzingsbeslis-

35. Kücükdeveci, punten 28, 33 en 36-37.

36. Dansk Industri, punten 26-27.

37. Doordat het Hof van Justitie in dezelfde zin waarin het verwijst naar het algemene verbod van discriminatie op grond van leeftijd verderop overweegt dat de nationale rechter ' (...) indien nodig elke met dit verbod [cursivering; SWH] strijdige nationale bepaling buiten toepassing moet laten' (punt 35), kan mijns inziens niet worden ontkend dat dit de formele basis is voor het buiten toepassing laten. Zie voor het onderscheid tussen het de facto en het de jure toetsingskader, M. De Mol, 'Kücükdeveci: Mangold revisited - horizontal direct effect of a general principle of EU law', European constitutional law review 2010, p. 300.

38. HvJ 24 januari 2012, zaak C-282/10, Dominguez, ECLI:EU:C:2012:33, punt 23, en in het bijzonder punten 43-44. 
sing baseert het Deense Hooggerechtshof zich op de conclusie van advocaat-generaal Trstenjak bij het arrest Dominguez, en de kanttekeningen die zij met het oog op het rechtszekerheidsbeginsel plaatst bij de wijze van doorwerking in Mangold en Kücükdeveci ${ }^{39}$ Meer in het bijzonder gaat het om het bezwaar dat het Hof van Justitie heeft verklaard dat '(...) een regeling die nadelige gevolgen voor particulieren heeft, duidelijk en nauwkeurig is en dat de toepassing ervan voor de justitiabelen voorzienbaar is'. ${ }^{40}$ Omdat het voor een particulier onduidelijk is wanneer een algemeen rechtsbeginsel, zoals dat concreet gestalte heeft gekregen in een richtlijn, prevaleert boven nationaal recht, leidt dit tot dezelfde rechtsonzekerheid die het Hof van Justitie juist probeerde te vermijden door horizontale rechtstreekse werking van richtlijnbepalingen uit te sluiten. ${ }^{41}$ Het door advocaat-generaal Trstenjak op dit specifieke niveau geformuleerde bezwaar, dat door het Deense Hooggerechtshof naar voren wordt gebracht, raakt, evenals de overwegingen van het Hof van Justitie betreffende de werking in tijd van de door hem gegeven uitlegging, aan de algemenere vraag wat het belang is van de mogelijkheid om de omvang van een uit het Unierecht voortvloeiende verplichting te kennen. Het onderscheid dat het Deense Hooggerechtshof daarbij maakt met het oog op de specifieke aard van de doorwerkingsroute à la Mangold en Kücükdeveci werd echter kennelijk door het Hof van Justitie niet voldoende relevant geacht om een afzonderlijke, daarop toegespitste, benadering te vereisen. Dit leid ik af uit de omstandigheid dat het Hof van Justitie het meer specifieke probleem waarop het Deense Hooggerechtshof het oog lijkt te hebben gehad (slechts) plaatst in het bestaande kader van (uitzonderingen op) de werking in tijd van de door hem gegeven uitlegging. In aanvulling hierop merk ik op dat ik mij kan voorstellen dat ook hier het belang van de volle werking van het Unierecht een rol speelt. Het Hof van Justitie ziet ruimte voor een uitzondering op de gevolgen van zijn arresten in beperkte, nader omschreven, omstandigheden. Echter, de door het Deense Hooggerechtshof voorgestelde uitwerking van het rechtszekerheidsbeginsel houdt in dat toepassing van de doorwerkingsroute à la Mangold en Kücükdeveci voor particulieren niet op voorhand is te voorzien en betreft de aard van deze doorwerkingsroute als zodanig. Om die reden zou een met het bezwaar van het Deense Hooggerechtshof corresponderende uitzondering mijns inziens een veel breder bereik hebben dan het enkel in uitzonderlijke omstandigheden afsluiten van de doorwerkingsroute à la Mangold en Kücükdeveci. Daarvoor ziet het Hof van Justitie geen ruimte.

\section{Ter afsluiting}

Met het arrest Dansk Industri onderstreept het Hof van Justitie het belang van de volle werking van het Unierecht. Dit doet het allereerst door in zijn antwoord op de tweede prejudiciële vraag de verplichting tot richtlijnconforme interpretatie te bespreken - ondanks de conclusie van het Deense Hooggerechtshof dat zo een interpretatie niet mogelijk is - en te overwegen dat het de nationale rechter niet is toegestaan enkel op basis van vaste rechtspraak de mogelijkheid van een richtlijnconform uitlegresultaat uit te sluiten. Met dit oordeel doorkruist het Hof van Justitie niet de bevoegdheid van de nationale rechter te oordelen over de interpretatie van nationaal recht. Of het Deense Hooggerechtshof uiteindelijk toch een richtlijnconforme interpretatie onderneemt, is moeilijk in te schatten aan de hand van het arrest. Wellicht zijn er andere redenen dan het enkel bestaan van vaste rechtspraak die zich daartegen verzetten. De mogelijkheid om tot een dergelijke conclusie te komen wordt hem niet ontnomen door het Hof van Justitie. In de tweede plaats volgt het Hof van Justitie de doorwerkingsroute à la Mangold en Kücükdeveci door te overwegen dat, zelfs wanneer een richtlijnconforme interpretatie daadmerkelijk (dat wil zeggen op andere gronden) niet mogelijk is, de nationale bepaling die in strijd is met het algemene verbod van discriminatie op grond van leeftijd buiten toepassing moet worden gelaten. Deze doorwerkingsroute draagt bij aan de volle werking van het Unierecht, maar is tevens controversieel. $\mathrm{Zij}$ is onder andere bekritiseerd met het oog op het rechtszekerheidsbeginsel. Het Hof van Justitie ziet echter geen aanleiding om in het licht van het rechtszekerheidsbeginsel een uitzondering te formuleren op het specifieke niveau van de doorwerkingsroute à la Mangold en Kücükdeveci. Daarmee is de bestaanszekerheid van deze route bevestigd. content/assets/ecer/ecer/import/hof_van_justitie/nieuwe_hofzaken_ inclusief_verwijzingsuitspraak/2014/c-zakennummers/c-441-14verwijzingsbeschikking.pdf> (geraadpleegd op 26 juli 2016).

40. Conclusie van A-G Trstenjak bij Dominguez, punt 164

41. Conclusie van A-G Trstenjak bij Dominguez, punt 164 